\title{
Short communication: Replacement heifer mortality from weaning until second mating in seasonal-calving, pasture-based dairy herds in New Zealand
}

\author{
W. A. Mason, ${ }^{1 *} \odot$ E. L. Cuttance, ${ }^{1} \odot$ R. A. Laven, ${ }^{2} \odot$ and C. V. C. ${ }^{2}{ }^{\circ} y n^{3} \odot$ \\ ${ }^{1}$ VetEnt, 49 Benson Road, Te Awamutu 3800, New Zealand \\ ${ }^{2}$ Massey University, College of Veterinary Science, Palmerston North 4442, New Zealand \\ ${ }^{3}$ DairyNZ Ltd., Private Bag 3221, Hamilton 3240, New Zealand
}

\begin{abstract}
The primary aim of this prospective study was to determine the postnatal mortality risk of replacement dairy heifers from weaning until the start of their second mating period ( $\sim 27$ mo of age) in seasonal-calving, pasture-based dairy herds. Data were analyzed from 24 farms from the Waikato $(\mathrm{n}=15)$ and Canterbury $(\mathrm{n}=$ 9) regions of New Zealand. All animals included in the study had an identified weaning date. From this point onward, data on animals that were euthanized, died unassisted, were culled, or were sold were recorded by the farmer on the home farm or by the grazier, according to animal location, and validated using calving, mating, culling, and sold records in their herd improvement database (MINDApro LIC, Newstead, Hamilton, New Zealand). The mortality risk from weaning to the start of the second mating period was calculated by dividing the number of deaths by the total number of enrolled animals at weaning. Mortality rate was calculated by dividing the number of deaths over the study period by the total days at risk, and reported as the mortality rate per $100 \mathrm{cow}$ years; this measure was also calculated as the mortality rate per farm. A total of 3,770 animals from 24 farms had data from weaning until the farm planned start of mating when animals were $\sim 27$ mo old. The animal-level mortality incidence risk from weaning ( $\sim 13$ wk of age) to the start of their second mating ( $\sim 27$ mo old) was $2.7 \%$ (95\% confidence interval: 2.2 to $3.3 \%$; 102 deaths $/ 3,770$ animals). The median farmlevel mortality incidence risk was $3.0 \%$, with a range across farms from 0 to $7.9 \%$. There was a total of 102 deaths over 2,429,362 cow days at risk, with the mean time at risk for the animals of $646 \mathrm{~d}$. The animal-level mortality was 1.53 deaths (95\% confidence interval 1.26 to 1.86 ) per $100 \mathrm{cow}$ years from weaning to second mat-
\end{abstract}

Received March 7, 2019.

Accepted August 25, 2019.

*Corresponding author: winston.mason@vetent.co.nz ing start date. The range in farm-level mortality rate was 0 to 4.52 deaths per 100 cow years. The hazard of death did not change throughout the study period. The results from this study are difficult to compare with international studies due to differences in study timing and duration, reporting method (mortality risk vs. mortality rate), and concerns with data validation. However, to the best of our knowledge, the results from this study indicate that postweaning, postnatal mortality under the New Zealand seasonal-calving, pasturebased system is lower than most other reported studies. Key words: postnatal mortality, calf, postweaning, death

\section{Short Communication}

Mortality and associated health issues in female dairy cattle are of growing interest worldwide as consumers increasingly consider animal welfare when purchasing food (Verbeke, 2009). Furthermore, dairy animal mortality results in substantial economic cost to the farm system, depending upon the timing and cause of death (Rogers et al., 1988; Tozer and Heinrichs, 2001). An increasing body of research is, therefore, investigating the incidence of mortality and associated risk factors at various stages of a dairy animal's life, which contributes knowledge toward developing preventative strategies that reduce premature mortality, improve health and welfare, and increase lifetime productivity in dairy herds.

In calves and replacement stock, mortality is usually divided into 2 phases: (1) perinatal mortality, which typically refers to death of the fetus or calf before, during or within 24 to $48 \mathrm{~h}$ after calving at full-term $(>260$ d), and (2) postnatal mortality, which refers to mortality after the perinatal period for a defined time. Many international studies indicate that bovine mortality, particularly during the first $24 \mathrm{~h}$ of life, is increasing, thereby highlighting the importance of benchmarking and identifying potential risk factors (Harbers et al., 
2000; Meyer et al., 2001; Hansen et al., 2004; Compton et al., 2017). However, there are many challenges with obtaining well-documented, validated data on calf and replacement heifer mortality. Mortality at these stages is often poorly documented by producers, and there is misclassification of sold, culled, or euthanized animals, all of which are likely to affect mortality estimates. Data validation is also a significant issue in studies across all cow age groups (Compton et al., 2017). The direction and extent to which these biases affected the results in the reviewed studies is unknown and seldom commented on by the authors. The results from published studies are, therefore, often not directly comparable as the methods of data collection, which significantly affect data validity, are different.

Most studies published on postnatal mortality have been conducted in rearing systems where animals are housed indoors for significant portions of the year (Tyler et al., 1998; Svensson et al., 2006; Lombard et al., 2007). However, the studies vary widely in their definition of time of mortality risk or developmental age, with few covering the entire replacement heifer growth phase up to at least first calving. Furthermore, limited studies have been published in seasonal-calving, pasture-based systems, such as those practiced in New Zealand, Australia, Ireland, and parts of Europe and South America, where heifers are reared principally on pasture and fed limited nonforage feeds postweaning (Brickell et al., 2009; Brickell and Wathes, 2011; Cuttance et al., 2017b). An animal's management, disease risk, and nutrition are different in these systems, making it difficult establish practical on-farm changes and benchmark targets based on recommendations and data from housed systems.

We recently characterized both perinatal mortality and postnatal mortality until weaning along with associated risk factors in dairy calves managed under seasonal-calving, pasture-based systems in New Zealand (Cuttance et al., 2017b). The primary aim of this prospective study was to extend these measures to determine the postnatal mortality risk of replacement dairy heifers from weaning until the start of their second mating period ( $\sim 27$ mo of age). A secondary aim was to compare these data to the mortality data before weaning on those farms to determine relationships between mortality at different stages of heifer development.

The initial experimental design of this study along with data collection protocols are described in detail in Cuttance et al. (2017b). Briefly, this study was originally established as a prospective observational study and survey of 32 seasonal-calving, pasture-based dairy farms from the Waikato $(\mathrm{n}=19)$ and Canterbury (n $=13$ ) regions of New Zealand. The farms were chosen primarily from a cohort of 35 farms already randomly selected (from clients of the veterinary practice, VetEnt, in these regions) to be part of another study investigating the incidence, risk factors, and long-term effects of failure of transfer of passive immunity in dairy calves (Cuttance et al., 2017a, 2018a,b). The herd inclusion criteria were that cows calved in winter/spring (July to October) and the farmer was willing to keep a daily record on the sex, movement (sold, sent for slaughter), and status (alive, died unassisted, euthanized) of calves every day from the day of birth until they were moved from the milking (home) farm to a separate herd (grazier) where they were reared on predominantly grazed pasture. In addition, the grazier had to be willing to record all mortality and any stock movements during the entire period that the heifers were under their management (i.e., from when they first arrived at $\sim 6$ mo of age to when they returned to their farm of origin at $\sim 22$ mo of age after being seasonally mated at $\sim 15$ mo of age). The farmer then had to be willing to record all mortality and any stock movements from heifer return, through the calving period, during early lactation, and to the start of the second mating period $(\sim 27$ mo of age). If the farm selected from the initial systematic random sample did not meet these criteria, the next farmer on the list was chosen and assessed for the same criteria.

All animals included in the study had an identified weaning date and a permanent unique identification tag in its ear. From this point onward, data on animals that were euthanized, died unassisted, culled, or sold were recorded by the farmer on the home farm or by the grazier, accordingly to animal location. Animal identification numbers (ear tag numbers) were recorded alongside their movements.

On the 24 farms enrolled in a failure of transfer of passive immunity study that was carried out in parallel to the present study, we weighed all animals every $3 \mathrm{mo}$, which provided a physical validation of animal movements and losses. In addition, all data were validated for all enrolled farms using calving, mating, culling, and sold records on a herd improvement database (MINDApro LIC, Newstead, Hamilton, New Zealand). Any discrepancies or unknown animals were followed up with the farmer to ensure that every animal enrolled had an identified movement or status at the end of the present study.

From the 32 farms initially enrolled, data were analyzed from 24 (Waikato: $\mathrm{n}=15$, Canterbury: $\mathrm{n}=9$ ): one farm was removed as a welfare investigation took place; one farm was sold; one farm changed from the veterinary practice collecting the data; one farm had major, unresolvable issues with the electronic data re- 
Table 1. Herd descriptions from the 24 farms included in the analysis of mortality from weaning until the start of second mating $(\sim 27 \mathrm{mo})$

\begin{tabular}{lccc}
\hline Farm variable & Median & Minimum & Maximum \\
\hline Herd size at planned start of mating & 670 & 268 & 2,150 \\
Milk solids per cow (mean) & 378 & 295 & 478 \\
Area (ha) & 175 & 85 & 506 \\
Mean age at weaning (d) & 91 & 71 & 101 \\
Planned start of calving each year & July 25 & July 10 & August 5 \\
No. of calves enrolled & 150 & 45 & 431 \\
\hline
\end{tabular}

cords; and 4 farms were removed due to uncertainty in the accuracy of the recording and reluctance/inability of the farmer to follow up queries.

The study population was all female replacement calves that were born on farm. The mortality risk for the period from weaning to the start of the second mating period was calculated by dividing the number of deaths by the total number of enrolled animals at weaning; this was also reported at the farm level.

Data were collected for each animal to determine their days at risk. The start point for each animal was its weaning date, and the end point for each animal was either when it was sold, culled, died or, if it was still on the farm of origin during its first lactation, when it first became eligible for its second mating period after its first calving (i.e., at the start of the seasonal mating period for that farm when animals were $\sim 27$ mo old). The mean number of days at risk for the entire population was calculated and a histogram was produced for the time at risk and for when deaths occurred over the time at risk. A Kaplan-Meier survival curve was created based on the proportion of animals alive at a given day postweaning, accounting for censoring of sold, culled, and dead animals. Mortality rate was calculated by dividing the number of deaths over the entire study period by the total days at risk, and reported as the mortality rate per 100 cow years; this was also reported as the mortality rate per farm. An instantaneous hazard curve was produced for the number of deaths over the number of animals at risk per week. Finally, a univariable Cox proportional hazard model, with farm as a frailty term, was undertaken to assess if there was a difference between the 2 regions; no other potential risk factor was collected for this data set. Proportional hazards were assessed for violation using scaled Schoenfeld residuals against time (Therneau and Grambsch, 2000; Therneau, 2015).

The relationship between preweaning, postnatal mortality [defined from when an animal entered the rearing shed ( $\sim 24 \mathrm{~h}$ of age) to weaning ( 13 wk of age), as previously reported in Cuttance et al. (2017b)], and postweaning, postnatal mortality on the same farms were investigated using scatterplots, and using Spear- man rank correlation tests conducted between the preand postweaning mortality rates.

All data analyses were undertaken using $\mathrm{R}$ v3.3.3 ( $\mathrm{R}$ Core Team, 2017, R Foundation for Statistical Computing, Vienna, Austria).

A total of 3,770 animals from 24 farms had data collected from weaning ( $\sim 13 \mathrm{wk}$ of age) until the planned start of mating when animals were $\sim 27$ mo old. Descriptions of the farms are presented in Table 1 . In 22 out of the 24 farms, animals left the farm of origin at approximately $5 \mathrm{mo}$ of age (range 3 to $6 \mathrm{mo}$ ) and remained off farm (i.e., at the grazier) until a mean age of 22 mo (range 18 to $23 \mathrm{mo}$ ); on 2 farms in the North Island, animals remained on the farm of origin for the entirety of the study.

The animal-level mortality incidence risk from weaning to the start of their second mating period was $2.7 \%$ (95\% CI $2.2 \%$ to $3.3 \%$; 102 deaths $/ 3,770$ animals). The median farm-level mortality incidence risk was 3.0\%, with a range across farms from $0 \%$ on 2 farms to $7.9 \%$ on one farm.

A total of 2,833 calving events were recorded from the 3,770 enrolled animals (75.1\%). However, 519 animals were also recorded as sold and removed from the study after the point of sale; these could have also had a calving event that was not recorded in the current data set.

A total of 102 deaths (88 deaths, 14 euthanized) occurred over 2,429,362 cow days at risk, with the mean length of the study period for each calf being $646 \mathrm{~d}$ from weaning (Figures 1 and 2a). The mortality rate was 0.00004 deaths per cow day, which was equivalent to 1.53 deaths (95\% CI 1.3 to 1.9 ) per 100 cow years from weaning to second mating (i.e., for every 100 animals that are reared, on average, 1.5 die per year). The range in farm-level mortality rate was 0 to 4.52 deaths per 100 cow years (Figure 1). A Kaplan-Meier curve animal survival is presented in Figure 2a. The hazard of death did not change throughout the study period (Figure 2b), with smoothed confidence intervals for the weekly instantaneous hazard overlapping for entire study period. There was no difference in the mortality hazard between the Waikato and Canterbury regions; 


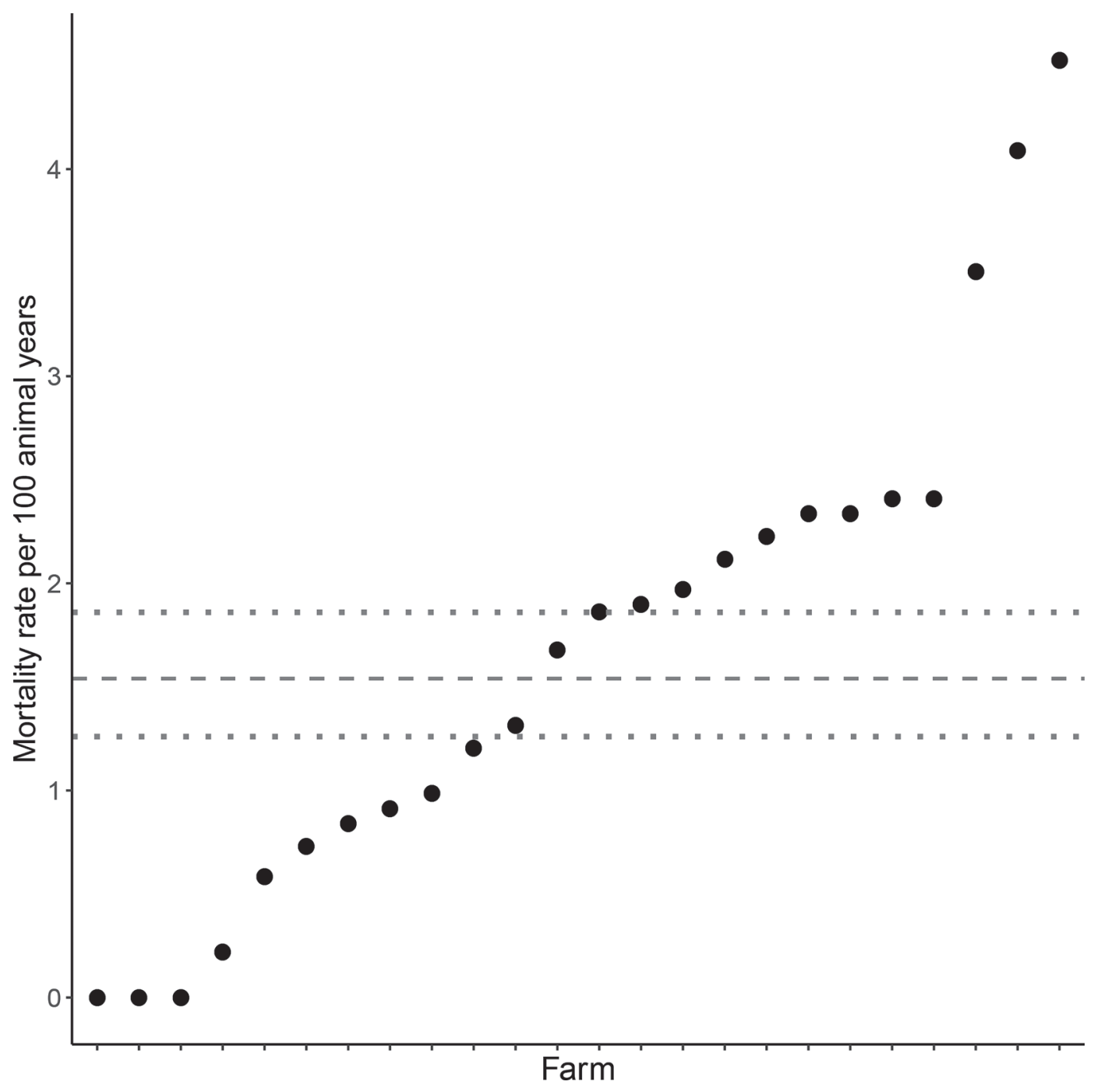

Figure 1. Dot plot of the mortality rate per 100 animal years on 24 different farms from weaning to approximately 27 mo of age (start of the second mating period); dashed horizontal line is the mean mortality rate per 100 animal years across the study population, and 2 dotted lines are the lower and upper confidence intervals for mean mortality rate per 100 animal years.

animals from Waikato farms had a hazard ratio of 1.18 (95\% CI 0.6 to 2.4 ) relative to animals from farms in Canterbury. The frailty term for farm was significant though $(P=0.003)$, indicating a difference in the hazards of mortality between farms.

No significant relationship $(P>0.05)$ was observed between preweaning, postnatal mortality rate (previously reported in Cuttance et al., 2017b) and postweaning, postnatal mortality rate. That is, farms that had a greater than average preweaning mortality did not have a greater than average mortality after weaning. The Spearman rank correlation coefficient identified a low degree of correlation and was not significantly different to zero (rho $=-0.25, P=0.24$ ). This figure also illustrated the greater death rate preweaning compared with postweaning.
The mortality risk in this study of $2.7 \%$ and mortality rate of 1.53 deaths per 100 cow years (95\% CI 1.26-1.86) are low relative to other published studies (Lombard et al., 2007; Brickell et al., 2009; Brickell and Wathes, 2011); however, directly comparing and interpreting between studies is very challenging for several reasons.

First, the timing and duration of data collection are highly variable across published studies. In many studies, authors report mortality from birth to a range between 90 to $180 \mathrm{~d}$ of age (Ortiz-Pelaez et al., 2008; Torsein et al., 2011; Azizzadeh et al., 2012), with no separation of pre- and postweaning mortality. The study by Brickell and Wathes (2011), however, had one of the most comparable timeframes and management systems to the present study. The authors reported a 

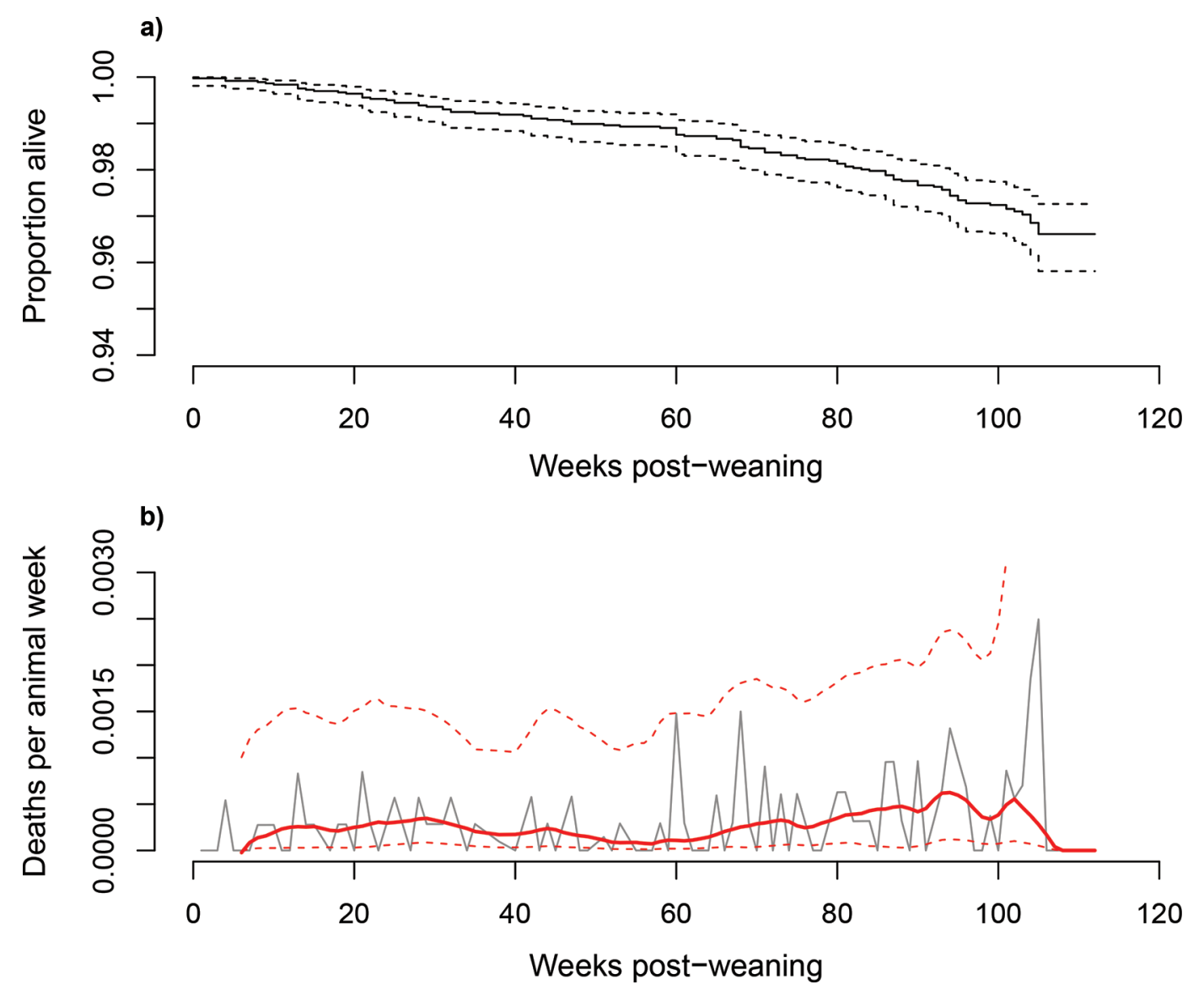

Figure 2. (a) A Kaplan-Meier survival curve with 95\% CI (dashed lines) of the proportion of animals still alive over time following weaning. (b) Weekly instantaneous hazard of death over the total number of weeks at risk per animal. Light gray: weekly instantaneous hazard; solid red line: smoothed weekly instantaneous hazard; dashed red lines: 95\% CI of smoothed instantaneous hazard.

mortality percentage estimate of $6 \%$ (excluding euthanasia) between 1 mo of age until the start of the first lactation on 18 pastoral dairy farms in England, but they only monitored a total of 468 animals. Svensson et al. (2006) reported mortality risks of $0.9 \%$ and $2.2 \%$ in $~ 9,000$ heifers from 91 to $210 \mathrm{~d}$ old and 211 to 810 $\mathrm{d}$ old, respectively, in the only other data set that we are aware of with a comparable timeframe to the present study; however, their animals were housed indoors. Thus, direct comparisons are limited, reflecting a similar timeframe and management system to the present study.

Second, another issue reducing comparability between studies is variation in the measure of mortality. Mortality is commonly reported as a simple mortality risk or percentage mortality (i.e., number of animals that died/the number of animals at the start). However, this measure does not account for the timing of an animal's death, nor animal movements (purchases, sales, or culls) that can bias the denominator (number at start) or numerator (number that died). In contrast, measuring days at risk allows animals to contribute data to the study even if they are sold or moved. Furthermore, mortality risk does not account for the timing of an animal's death (which can be important). Mortality risk cannot be simply converted to a mortality rate by multiplying by the length of the study period. For example, in our study, the mean time at risk was 646 d. If we were to approximate the time at risk for every heifer and assume all animals were enrolled to 27 mo of age, then the time at risk estimate for each heifer would have been $710 \mathrm{~d}$, which would have reduced the overall estimate of the mortality rate by $9 \%$, or from 1.53 to 1.39 deaths per 100 cow years. Thus, to compare our data to previous studies we need to use days at risk to calculate mortality rate.

In this regard, our mortality rates in postnatal heifers were generally similar (Svensson et al., 2006) or less (Ortiz-Pelaez et al., 2008; Brickell and Wathes, 2011) than those from previous studies. Svensson et al. (2006) reported mortality rates between 90 to $210 \mathrm{~d}$ old and 211 and $810 \mathrm{~d}$ old of 0.002 and 0.001 deaths per calf- 
month at risk, respectively. These rates are equivalent to 2.4 and 1.2 deaths per 100 cow years, respectively, which are comparable to our estimate of 1.53 deaths over a timeframe that included both these age periods. However, it is unclear from Svensson et al. (2006) how they calculated time at risk, which means that direct comparisons between studies are still challenging. Brickell and Wathes (2011) reported mortality rates of $3.6,3.8$, and $0.2 \%$ from 1 to 6 mo of age, 6 mo to first mating, and first mating to calving, respectively. These rates equate to $9,4.7$, and 0.26 deaths per 100 cow years, or 3.4 deaths per 100 cow years over the entire time period. We report consistent, lower mortality rates in the present study of 0.92 deaths per 100 cow years from weaning to $\sim 6$ mo of age, 1.49 deaths per $100 \mathrm{cow}$ years from $\sim 6$ mo to the start of mating in the dairy herd (second mating period for the heifers), and 1.53 deaths per 100 cow years over the entire period at risk. This lower mortality rate is despite the present study including the transition period around first calving, which is reported to increase the risk of heifer death due to associated calving problems and, to a lesser extent, metabolic and infectious diseases (Peeler et al., 1994; Goff and Horst, 1997).

A third issue reducing comparability of mortality estimates between our study and previous literature is data quality. Many previous studies had little, if any, validation of data sets. In particular, retrospective analyses of large electronic data sets are often biased by poor recording of animal mortality and movements. For example, Ortiz-Pelaez et al. (2008) recorded that (depending on the location and year) between 56 and $88 \%$ of locations had no registered deaths, either because there were truly no deaths or, more likely, that deaths were simply not recorded. In the current prospective study, animal existence in the herd was visually verified at regular weighing events (20 farms), and data provided by farmers/graziers were substantiated against electronic records for calving, mating, sold, and culling events. Although there was still a reliance on farmer recording, we verified animal existence and movements in multiple ways. Any discrepancies were followed up with the farmer to clarify animal existence and movements; we investigated discrepancies for approximately 50 to 200 animals across the study, representing a small proportion of the total population studied. In a recent prospective study, Compton (2018) indicated that there was a discrepancy of about $2 \%$ between electronic records on cow removals and written on-farm records in a sample of 33 farms in New Zealand, but some farms had discrepancies of up to $8 \%$. It is unknown how many mortality and animal removal events are not recorded on New Zealand dairy farms. In our study, the farmers were primed and prompted regularly to record. We postulate that the discrepancies would likely be greater and of more significance to the data set if this study was performed using a much larger population of farms. We argue that our results have a high degree of internal validity relative to retrospective analyses of large electronic data sets typically in place for herd recording.

The limitation, however, of such studies with substantial data validation is that they are often relatively small, which may reduce the external validity of their results. For example, Brickell et al. (2009) reported a $3.4 \%$ postnatal mortality risk in 506 female calves between 1 to 6 mo of age across 19 dairy farms in southern England. However, one farm contributed half of all deaths recorded and, therefore, had a large upward bias on the overall results. Without that farm included the analysis, the overall mean mortality risk would have reduced to $1.7 \%$. In the present study, although there was large between-farm variation in mortality estimates, sufficient numbers of animals and farms were included so that farms with very low or high mortality did not significantly bias the overall mean mortality estimates. Nevertheless, our focus on internal validity potentially limited the external validity of our data set. The 24 farms (reduced from an initial 32) represented a small sample size of the New Zealand population of $\sim 11,750$ dairy farms (New Zealand dairy statistics, DairyNZ; https://www.dairynz.co.nz/publications/ dairy-industry/new-zealand-dairy-statistics-2017-18/). The initial sample size was based upon an opportunity to collect additional prospective measurements to other studies (Cuttance et al., 2017a,b). The farms chosen had strict inclusion criteria that focused on compliance; however, 8 farms were removed due to the inability to obtain accurate data. It is hard to know what effect this may have had on the data set, but this, in combination with the smaller sample size, may mean this data set is not fully representative of New Zealand dairy farms. Nevertheless, the study herds were typical of those from 2 major, geographically diverse dairying regions, and no significant differences were observed between average mortality hazards between these regions. This may have been due to insufficient sample size with only 102 deaths and 3,770 animals monitored, but the results supported that our mortality estimates are sufficient to indicate benchmarks to support farm management decisions.

No association was detected between postweaning mortality rates and preweaning mortality rates on the farms collected. However, each time period had a cluster of 3 to 6 farms (different farms for each time period) with markedly higher rates of mortality than other farms. Early identification and management of issues on these particular farms may be an efficient method of reducing overall mortality at an industry level. 
In conclusion, we estimated a postnatal mortality risk of $2.7 \%$ and a mortality rate of 1.53 deaths per 100 cow years during the period from weaning until second mating start date $(\sim 27 \mathrm{mo})$ in pasture-based dairy heifers. The results from this study are difficult to compare with international studies due to differences in study length, reporting method (mortality risk vs mortality rate), and concerns with data validation. However, to the best of our knowledge, the results from this study indicate that postweaning, postnatal mortality under the New Zealand seasonal-calving, pasture-based system is equivalent or lower than most other reported studies. These mortality estimates can be used to benchmark seasonal-calving, pasture-based dairy systems and provide a comparison for more intensive, housed systems.

\section{ACKNOWLEDGMENTS}

This study was funded by the New Zealand Ministry of Business, Innovation, and Employment (Wellington, NZ; contract number DRCX1302) and by New Zealand dairy farmers through DairyNZ Inc. (Hamilton, NZ; contract number RD1405). The authors gratefully acknowledge the participation and technical support of the enrolled farmers and Veterinary Enterprises Group Ltd. (Te Awamutu, New Zealand), respectively.

\section{REFERENCES}

Azizzadeh, M., H. F. Shooroki, A. S. Kamalabadi, and M. A. Stevenson. 2012. Factors affecting calf mortality in Iranian Holstein dairy herds. Prev. Vet. Med. 104:335-340.

Brickell, J. S., M. M. McGowan, D. U. Pfeiffer, and D. C. Wathes. 2009. Mortality in Holstein-Friesian calves and replacement heifers, in relation to body weight and IGF-I concentration, on 19 farms in England. Animal 3:1175-1182.

Brickell, J. S., and D. C. Wathes. 2011. A descriptive study of the survival of Holstein-Friesian heifers through to third calving on English dairy farms. J. Dairy Sci. 94:1831-1838.

Compton, C. W. R. 2018. The epidemiology of culling and mortality of New Zealand dairy cows. PhD Thesis. Veterinary Epidemiology, Massey University, Manawatu, New Zealand.

Compton, C. W. R., C. Heuer, P. T. Thomsen, T. E. Carpenter, C. V. C. Phyn, and S. McDougall. 2017. Invited review: A systematic literature review and meta-analysis of mortality and culling in dairy cattle. J. Dairy Sci. 100:1-16.

Cuttance, E. L., W. Mason, R. Laven, K. Denholm, and D. Yang. 2018a. Calf and colostrum management practices on New Zealand dairy farms and their associations with concentrations of total protein in calf serum. N. Z. Vet. J. 66:126-131.

Cuttance, E. L., W. Mason, R. Laven, J. McDermott, and C. Phyn. 2017a. Prevalence and calf-level risk factors for failure of passive transfer in dairy calves in New Zealand. N. Z. Vet. J. 65:297-304.
Cuttance, E. L., W. A. Mason, R. A. Laven, and C. V. C. Phyn. 2018b. The relationship between failure of passive transfer and mortality, farmer-recorded animal health events and body weights of calves from birth until 12 months of age on pasture-based, seasonal calving dairy farms in New Zealand. Vet. J. 236:4-11.

Cuttance, E. L., W. A. Mason, J. McDermott, R. A. Laven, S. McDougall, and C. V. C. Phyn. 2017b. Calf and replacement heifer mortality from birth until weaning in pasture-based dairy herds in New Zealand. J. Dairy Sci. 100:8347-8357.

Goff, J. P., and R. Horst. 1997. Physiological changes at parturition and their relationship to metabolic disorders. J. Dairy Sci. 80:1260-1268.

Hansen, M., I. Misztal, M. S. Lund, J. Pedersen, and L. G. Christensen. 2004. Undesired phenotypic and genetic trend for stillbirth in Danish Holsteins. J. Dairy Sci. 87:1477-1486.

Harbers, A., L. Segeren, and G. de Jong. 2000. Genetic parameters for stillbirth in the Netherlands. Interbull Bull. 117.

Lombard, J. E., F. Garry, S. Tomlinson, and L. Garber. 2007. Impacts of dystocia on health and survival of dairy calves. J. Dairy Sci. 90:1751-1760.

Meyer, C. L., P. J. Berger, K. J. Koehler, J. R. Thompson, and C. G. Sattler. 2001. Phenotypic trends in incidence of stillbirth for Holsteins in the United States. J. Dairy Sci. 84:515-523.

Ortiz-Pelaez, A., D. G. Pritchard, D. U. Pfeiffer, E. Jones, P. Honeyman, and J. J. Mawdsley. 2008. Calf mortality as a welfare indicator on British cattle farms. Vet. J. 176:177-181.

Peeler, E. J., M. Otte, and R. Esslemont. 1994. Inter-relationships of periparturient diseases in dairy cows. Vet. Rec. 134:129-132.

Rogers, G., J. Van Arendonk, and B. McDaniel. 1988. Influence of production and prices on optimum culling rates and annualized net revenue. J. Dairy Sci. 71:3453-3462.

Svensson, C., A. Linder, and S. O. Olsson. 2006. Mortality in Swedish dairy calves and replacement heifers. J. Dairy Sci. 89:4769-4777.

Therneau, T. M., and P. M. Grambsch. 2000. Modeling Survival Data: Extending the Cox Model. Springer-Verlag, New York, NY.

Therneau, T. M. 2015. A package for survival analysis in S. 2015. Version 2.38. Springer, New York, NY.

Torsein, M., A. Lindberg, C. H. N. Sandgren, K. P. Waller, M. Tornquist, and C. Svensson. 2011. Risk factors for calf mortality in large Swedish dairy herds. Prev. Vet. Med. 99:136-147.

Tozer, P. R., and A. J. Heinrichs. 2001. What affects the costs of raising replacement dairy heifers: A multiple-component analysis. J. Dairy Sci. 84:1836-1844.

Tyler, J. W., D. D. Hancock, S. E. Wiksie, S. L. Holler, J. M. Gay, and C. C. Gay. 1998. Use of serum protein concentration to predict mortality in mixed-source dairy replacement heifers. J. Vet. Intern. Med. 12:79-83.

Verbeke, W. 2009. Stakeholder, citizen and consumer interests in farm animal welfare. Anim. Welf. 18:325-333.

\section{ORCIDS}

W. A. Mason @ https://orcid.org/0000-0002-0006-7323

E. L. Cuttance ๑ https://orcid.org/0000-0003-0354-5295

R. A. Laven () https://orcid.org/0000-0002-8938-8595

C. V. C. Phyn $\odot$ https://orcid.org/0000-0002-4912-4069 